\title{
TRATAMIENTO DE ENDODONCIA EN UN PRIMER PREMOLAR INFERIOR CON TRES CONDUCTOS
}

\author{
${ }^{1}$ Karen Avendaño Calderón, ${ }^{2}$ Javier Niño-Barrera, ${ }^{3}$ Luis Fernando Gamboa Martínez \\ ${ }^{1}$ Estudiante F. de Odontología U. Nacional de Colombia, Colombia. \\ ${ }^{2}$ Especialista en Endodoncia U. El Bosque, Magíster en Ingeniería Biomédica U. Nacional de Colombia, Docente U. Nacional de Colombia, Colombia. \\ ${ }^{3}$ Especialista en Endodoncia U. El Bosque, Magíster en Epidemiología Clínica U. Javeriana, Docente U. El Bosque, Colombia.
}

Autor responsable de correspondencia: Luis Fernando Gamboa Martínez

Correo electrónico:fgamboa@hotmail.com

\section{RESUMEN}

Dada la importancia de la identificación y conocimiento de la anatomía del sistema de conductos previa a la realización de una terapia endodóntica, se hace indispensable conocer las posibles variaciones de cada diente y así idear un plan de tratamiento cuyo fin sea el éxito del mismo. El propósito de este artículo fue reportar un caso de un primer premolar inferior con tres conductos en el que se realizó un retratamiento endodóntico con método químico y mecánico en la Universidad Nacional de Colombia. Posteriormente, los conductos fueron tratados con la técnica de preparación telescópica y se obturaron con la técnica de condensación lateral sin complicaciones [Avendaño K, Niño-Barrera J, Gamboa LF. Tratamiento de endodoncia en un primer premolar inferior con tres conductos. Ustasalud 2013; 12: 134 - 137]

Palabras clave: Endodoncia, Periodontitis periapical, Pulpa dental.

\section{ENDODONTIC TREATMENT IN A MANDIBULAR FIRST PREMOLAR WITH THREE CANALS}

\section{ABSTRACT}

Based on the importance of identification and knowledge of the anatomy of the root canal system prior to the completion of endodontic therapy, it is essential to know the possible variations of each tooth and so devise a treatment plan whose purpose is success same. The purpose of this paper is to report a case held at the National University of Colombia in a first lower premolar with three canals, where a retreat with chemical and mechanical method was performed. Later passages were treated with Step Back technique and sealed with lateral condensation technique without complications.

Key words: Endodontics, Periapical periodontitis, Dental pulp.

Recibido para publicación: noviembre 13 de 2013. Aceptado para publicación: diciembre 20 de 2013.

\section{INTRODUCCIÓN}

Dentro de las garantías del éxito de un tratamiento endodóntico fundamentalmente se encuentra el conocimiento de la anatomía y morfología de los conductos y de la comprensión de la técnica para su tratamiento. ${ }^{1}$ Para alcanzar el éxito clínico en endodoncia todo el sistema de conductos radiculares debe ser preparado, desinfectado y obturado, por lo tanto las alteraciones en número y morfología de los conductos debe ser comprendida por el clínico previo a la iniciación del tratamiento. ${ }^{2}$

Las características anatómicas ideales de un diente para el tratamiento endodóntico como en el caso del primer premolar inferior con una mayor frecuencia de un conducto único, cónico y con un solo foramen constituyen la regla general. Sin embargo desde los estudios más antiguos hasta los más frecuentes sustentan las múltiples variaciones posibles en el sistema de conductos radiculares. ${ }^{2-4}$.
Dentro de las variaciones más frecuentes que poseen mayor relevancia es el número de conductos, a lo largo de la historia se han hecho múltiples estudios que pretenden establecer la prevalencia de dos, tres y hasta cuatro conductos; ${ }^{5-7}$ igualmente se han llevado a cabo revisiones donde se analizan estudios previos sobre el número de conductos y sus resultados para el primer premolar inferior. ${ }^{4,8}$

A pesar de que los valores de prevalencia de tres conductos en el primer premolar inferior varían de $0,5 \%$ a $1,26 \%,{ }^{9,10}$ no es claro cómo es la disposición de ellos en la cámara pulpar y aunque hay un estudio en población colombiana, este no presenta radiografias o imágenes de la tintura con tinta china en dientes diafanizados ni descripción de algún manejo de casos. Por lo tanto, el objetivo del presente reporte es presentar un caso de un primer premolar inferior con tres conductos en población colombiana junto con las radiografías del procedimiento. 


\section{REPORTE DE CASO}

Paciente de sexo femenino de 50 años de edad, remitida a la clínica de endodoncia de pregrado de la Facultad de Odontología de la Universidad Nacional de Colombia para realizar el retratamiento endodóntico del diente 34 , la paciente se presenta asintomática.

Refiere tratamiento endodóntico previo del diente 34 realizado hace cinco años. Al examen clínico se observa el material de obturación expuesto al medio oral con seis meses de evolución, destrucción coronal del $90 \%$, leve dolor a la percusión vertical. $\mathrm{Al}$ examen radiográfico se observa imagen radiopaca ocupando el espacio de los conductos radiculares compatible con material de obturación, se observan dos conductos separados entre sí que finalizan en un mismo punto a $3 \mathrm{~mm}$ del ápice radiográfico, y adicionalmente se observa zona radiolucida apical del diente 34 (Figura 1). Se diagnostica como periodontitis apical asintomática y se propone realizar retratamiento endodóntico convencional.

Se inicia el tratamiento con anestesia local del diente 34 con técnica dentario inferior y se realiza aislamiento absoluto del campo operatorio con dique de goma, a continuación se retiró el material de obturación de la cámara con uso de cucharilla y fresa redonda número 2 , posteriormente se procedió a realizar la desobturación con la aplicación de xilol en la entrada de los conductos y se hizo la exploración con lima de primera serie \# 35. Se observaron entradas a dos conductos obturados una vestíbulo distal y otra lingual; a la exploración clínica se ubicaron inicialmente los dos conductos mencionados, pero al volver a colocar las dos limas se observó que un instrumento tomaba una dirección diferente y se sospechó de la presencia de un tercer conducto.

La presencia de este tercer conducto fue confirmada por magnificación a 10x con microscopio óptico Seiler ${ }^{\circledR}$. Mediante las imágenes radiográficas se logró observar el trayecto de este tercer conducto ubicado hacia la superficie vestíbulomesial, se confirmó que la lima estuviera dentro de un conducto con el uso del localizador apical Root ZX II ${ }^{\circledR}$ y se verificó con una radiografia (Figuras 2 y 3 ).
En la segunda sesión se utilizó anestesia local y aislamiento absoluto del campo operatorio, se procedió a verificar la desobturación completa de los conductos lingual y vestibulodistal, confirmándola con una radiografia (Figura 4) igualmente en esa radiografía se tomó la conductometría confirmando las medidas obtenidas con localizador apical. En la imagen se evidenció que se alcanza una adecuada longitud, mejorando así la del tratamiento inicial. Los datos de la conductometria definitiva y limas apicales principales se presentan en la Tabla 1.

Se inició la preparación biomecánica,tras la determinación de las limas principales apicales (Tabla 1), se continuó preparando los conductos con la técnica telescópica y se usaron tres instrumentos por encima del último que se utilizó en apical, apoyándose en todas las paredes y recapitulando con la lima apical principal. Durante todo el procedimiento se irrigaron los conductos con hipoclorito de sodio al 5,25\%.

En la tercera sesión bajo anestesia local y aislamiento absoluto del campo operatorio, el sistema de conductos se irrigó y durante todo el procedimiento de preparación se mantuvieron húmedos los conductos, se secaron con conos de papel estéril y se procedió a obturar los conductos con conos de gutapercha con técnica de condensación lateral, se utilizó como cemento sellador Topseal ${ }^{\circledR}$, se remitió para restauración definitiva. Finalmente se tomó una radiografía final de la obturación en diferentes angulaciones horizontales (Figuras 5 y 6 ).

\section{DISCUSIÓN}

Para entender la variabilidad en el número de conductos se ha establecido mediante la investigación, que tanto el sexo como el grupo étnico juegan un papel importante en la determinación morfológica del sistema de conductos. En comparación con los pacientes blancos los de raza negra tienen un mayor número de conductos supernumerarios tanto en el primer premolar inferior como en el segundo premolar inferior. ${ }^{11}$

El sistema de conductos del primer premolar inferior es muy variable y los estudios en la población colombiana así lo demuestran, las variantes más frecuentes en esta población según la clasificación

Tabla 1. Datos de conductometría y lima principal apical.

\begin{tabular}{ccc}
\hline Conducto & Longitud de trabajo $(\mathrm{mm})$ & Lima principal apical \\
\hline Distovestibular & $17 \mathrm{~mm}$ & 30 \\
Vestíbulomesial & $16 \mathrm{~mm}$ & 30 \\
Lingual & $17 \mathrm{~mm}$ & 25 \\
\hline
\end{tabular}



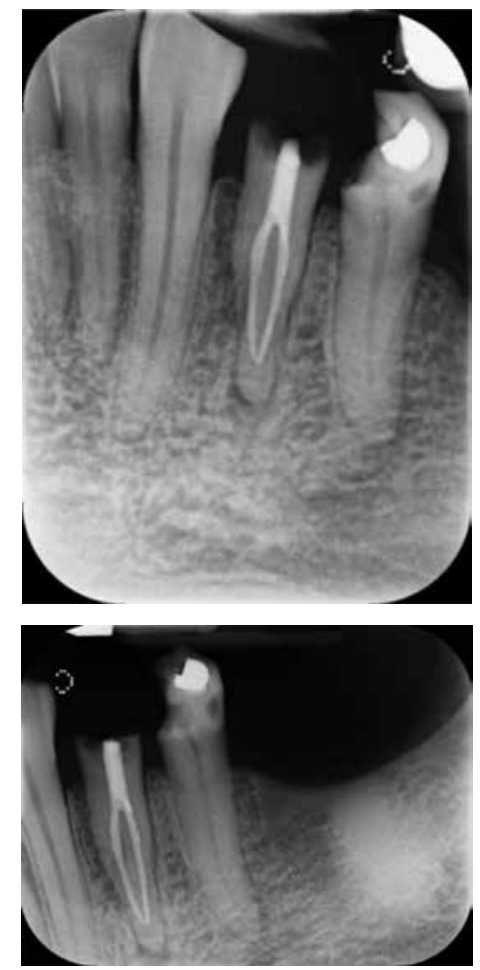

Figura 1. Radiografias iníciales del primer premolar mandibular.
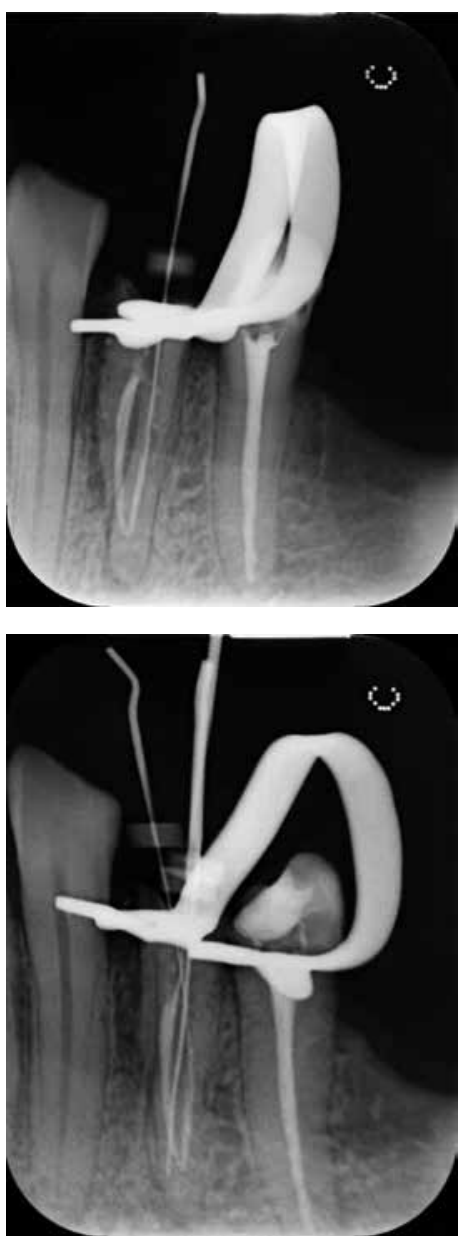

Figura 2 y 3. Radiografias de la conductometria tentativa y la ubicación de los tres conductos.

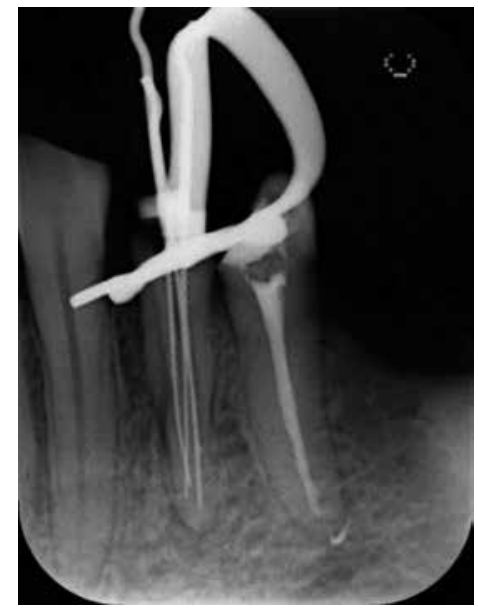

Figura 4. Radiografia de la conductometría.

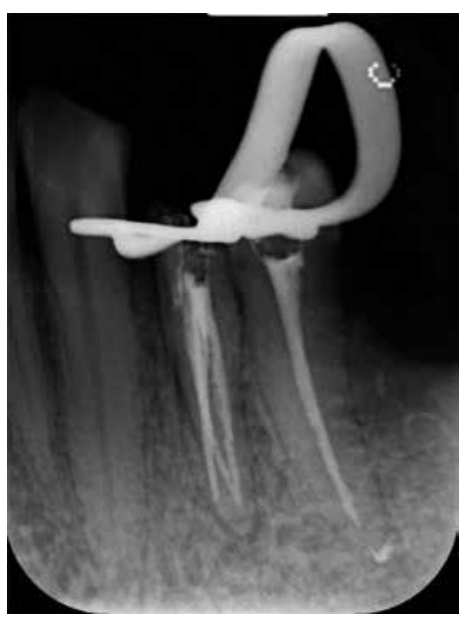

Figura 5. Obturación definitiva.

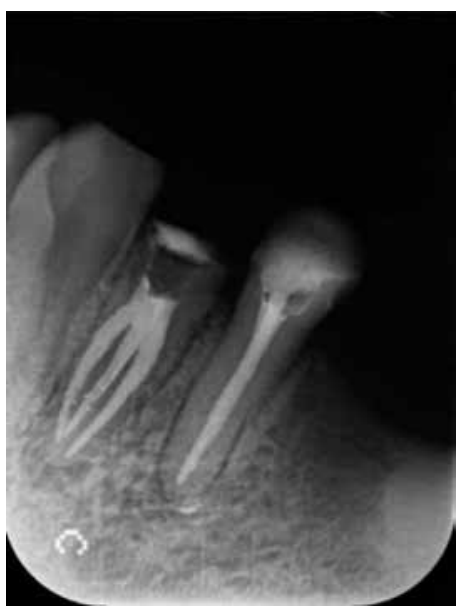

Figura 6. Obturación definitiva.

de Vertucci son los tipo $\mathrm{V}$ que corresponde a un conducto que se divide en dos en la porción apical con un $21,11 \%$, el número de conductos se reportan así: tipo I: un único conducto con $67,8 \%$, tipo IV: 2 conductos separados con un 4,27\%, y tipo VIII: tres conductos separados con $1,26 \%{ }^{10}$ La prevalencia 
del tercer conducto en el primer premolar inferior oscila alrededor del $0,5 \%$ según los estudios de referencia internacional. ${ }^{11}$

Uno de los componentes más importantes en el planeamiento del tratamiento es el análisis de la radiografía inicial en busca de conductos adicionales, así como de la anatomía del sistema de conductos, en este caso en el que ya había un tratamiento previo se dificultó la ubicación del tercer conducto en la radiografia inicial, ya que solo se encontraban obturados dos conductos y teniendo en cuenta que la radiografía es una imagen en dos dimensiones es posible que un conducto adicional no sea visible en esta radiografía ya sea por la posición del mismo con relación a los otros conductos, la angulación horizontal con la que se toma la radiografia, la calidad de la imagen o incluso por la obturación inicial en la que se espera sea adecuada de todo el sistema de conductos, en la actualidad para este tipo de casos podría llegar a ser útil la tomografía de haz de cono, sin embargo en el presente caso no se realizó, ya que el tercer conducto fue localizado clínicamente y observado con una radiografia periapical.

La valoración clínica del piso de la cámara pulpar es de vital importancia para la localización del tercer conducto, en el presente caso reportado,cuando se realizó la exploración de la cámara al introducir el instrumento este tomaba una dirección más mesial con relación al punto de referencia coronal, para el conducto distal vestibular igualmente se observó cómo variaba la dirección de la lima, y para determinar la entrada del tercer conducto se siguió el mismo principio. Debe tenerse una correcta visibilidad y acceso con ayuda de magnificación en este caso a 10x. Fue igualmente necesario ampliar la apertura lo suficiente para permitir la instrumentación en este aspecto es útil el uso de ultrasonido con el fin de escudriñar adecuadamente la cámara pulpar en busca de más conductos. Se han sugerido otras técnicas para la ubicación de conductos como el uso de azul de metileno, para que se adhiera al tejido orgánico presente en la entrada de los conductos y la observación del efecto de burbujas de champagne que se presentara en la entrada de un conducto cuando se genere una turbulencia.

\section{Conclusiones}

- Aunque la frecuencia de un tercer conducto en el primer premolar inferior en población colombiana está reportada en un 1,26\%, los estudios en su mayoría europeos ubican en $0,5 \%$ la probabilidad de encontrar un tercer conducto en primeros premolares inferiores, lo que refuerza la afirmación de que la anatomía radicular está fuertemente influenciada por la etnia
- En todo tratamiento endodóntico es importante el uso de magnificación e iluminación, el ultrasonido, el uso de localizador apical para detectar si se esta dentro de un conducto o no, el uso de radiografias con distintas angulaciones y el conocimiento de la anatomía normal, para llevarlo a cabo con éxito.

\section{BIBLIOGRAFÍA}

1. Lin LM, Skribner JE, Gaengler P. Factors associated with endodontic treatment failures. J Endod. 1992; 18 (12): 625 $-627$.

2. Albuquerque D, Kottoor J, Hammo M. Endodontic and clinical considerations in the management of variable anatomy in mandibular premolars: a literature review. BioMed Res Int. 2014. Epub 2014 may 8.

3. Vertucci FJ. Root canal anatomy of the human permanent teeth. Oral Surg Oral Med Oral Pathol. 1984; 58 (5): 589 - 599.

4. Cleghorn BM, Christie WH, Dong CC. The root and root canal morphology of the human mandibular first premolar: a literature review. J Endod. 2007; 33 (5): 509 - 516.

5. Kararia N, Chaudhary A, Kararia V. Mandibular left first premolar with two roots: A morphological oddity. Contemp Clin Dent. 2012; 3 (2): 234 - 236.

6. Kakkar P, Singh A. Mandibular first premolar with three roots: a case report. Iranian Endod J. 2012; 7 (4): 207 - 210.

7. Du Y, Lee AH, Zhang C. Mandibular first premolar with four canals. J Investig Clin Dent. 2013; 4 (1): 64 - 66.

8. Li X, Liu N, Ye L, Nie X, Zhou X, Wen X, et al. A microcomputed tomography study of the location and curvature of the lingual canal in the mandibular first premolar with two canals originating from a single canal. J Endod. 2012; 38 (3): 309 - 312.

9. Vertucci FJ. Root canal morphology of mandibular premolars. J Am Dent Assoc. 1978; 97 (1): 47 - 50.

10. Alfonso-Rodríguez CA, Acosta-Monzón EV, López-Marín DA, Lancheros-Bonilla S, Moreno-Abello GC, Tovar ME. Description of the root canal system of mandibular first premolars in a colombian population. Oral Sci Int. 2014; 11: 35 - 36.

11. Tinelli ME, Ferreira G, Gómez N, . Variantes étnicas de la topografia de los conductos radiculares. EJER. 2011; 10 (2): $553-557$.

Correos electrónicos de los autores:

Karen Avendaño Calderón: kaavendanoc@unal.edu.co Javier Niño Barrera: jlninob@unal.edu.co Luis Fernando Gamboa Martínez: fgamboa@hotmail.com 